\title{
Study on Occurrence of Legal Argumentation
}

\author{
Yan $\mathrm{Lu}$ \\ College of Political Science and Law, Qujing Normal University \\ Qujing 655011, Yunnan, China \\ E-mail: prettyluyan@sohu.com,35100915@qq.com
}

Received: February 12, 2011 Accepted: February 28, $2011 \quad$ doi:10.5539/ass.v7n6p190

\begin{abstract}
The argumentation is a rational thinking activity, while legal argumentation is a specific research achievement of the theory of argumentation in study of law. It began in the sixties and seventies of the 20th Century. The theory attracted a great amount of research passion, which came from jurists and philosophers. At the time when legal argumentation received favor of study by lawyers and philosophers, it was gradually developed into a new studying paradigm for theory.
\end{abstract}

Keywords: Legal argumentation, The origin of thought, Methodology

Legal argumentation theory is a sort of theoretical research paradigm that was gradually developed in Europe in the sixties and seventies of the $20^{\text {th }}$ Century. At the beginning of its formation, it was mainly developed in the field of legal theory and philosophical field. At present, it is regarded as one of legal methodologies, and even as an integral part of legal logic. (Xia Zhenpeng, 2004, p270) Until the seventies of the last century, legal argumentation theory had not aroused zeal of legal practitioners and argumentation theoretical experts in study on it. Ever since then, legal argumentation was gradually developed into an independent research subject.

\section{Definition of the concept of argumentation}

Argumentation exists generally in the social life, but the concept of argumentation has, so far, not had a unified academic definition, because academics prefer to conduct studies from different perspectives. According to Fiatrice, "Argumentation plays an important role in law. All those who have proposed a legal proposition have to support argumentation of their proposition. When lawyers submit a law case to the court, he also has to resort to argumentation to justify his case. Likewise, when a judge makes a verdict, he has to resort to argumentation to support his verdict (Eveline T. Feteris, 2005, p3). According to Yan Jue-an, "argumentation means that one illustrates begrunden to support a certain Behauptung or Urteil (Jiao Baoqian, 2006, p49). Eemeren et al defined argumentation as such, "a sort of proverb and a social persuasive behavior --- one puts forward a group of proposals and testifies or refutes a certain disputable viewpoint in front of each rational "judge", with the purpose to strengthen or weaken audience or readers' acceptance degree of this viewpoint." Zhenxie, 2001, p87). Fiatrice and Yan Jue-an regarded argumentation as a process of proving. That is, to put forward a certain reason to support correctness of a certain proposal, statement or judgment. By contrast, Eemeren advocated that argumentation was a process of testifying and refuting --- in the process of argumentation, a disputer has to put forward grounds of argument to prove his own proposal, but has to refute the viewpoints of the opponent so as to achieve the purpose of persuading the audience. Based on consideration of judicial reality, argumentation is an overall process of testifying and refuting and exists extensively in all kinds of rational thinking activities, a sort of typical practical and rational activity.

Legal argumentation is the specific representation of the theory of argumentation in the research field of law. Alexy said, "Legal argumentation can be differentiated to juristic (dogmatics) argument, dierichterliche Beratung, dispute in the court, discussion of the legislative body (committee and standing committee) on legal issues, debate among students, lawyers, the government or legal advisers in enterprises and debate of the media on relevant legal issues with the feature of legal argument. (Robert Alexy, 2002. p340-342) Ge Hongyi proposed that legal argumentation was mainly concerned with how to prove correctness and legitimacy of relevant legal proposals of the following in a way that conforms to the logic, fact or rationality: legislative opinion, judicial decision (including judicial decree, verdict, decision making and the process) and legal statement (legal statement by the party concerned in the court) (Ge Hongyi, 2004). Ji Weidong proposed that legal argumentation was one of the new developmental trends presented in the practical jurisprudence; Chen Jinzhao thought that 
legal argumentation fell within the research scope of proposition discipline; Zheng Yongliu put forward that legal argumentation was one of the legal means for contemporary legal methods to get expanded.

In one word, legal argumentation is within the research scope of legal methodology, testification and refutal within the thinking field and is the overall process of thinking and expressing, which resorts to oral or written language symbols to convey information to the outside world. Through proposing definite proof and cause, legal argumentation employs the method of testification or refutal to demonstrate legitimacy and legality of certain legal opinion, legal statement, legal doctrine and legal decision. Legal argumentation exists within the fields of legislation, application of law, judicial decision, judicial education and jurisprudence, etc, and is a sort of practical and rational activity. The theory of legal argumentation offers rational discussion procedure with the content of argumentation rules for legitimacy of legal argumentation itself, with the aim of ensuring participants of legal argumentation are able to discuss a legal issue in a rational way and avoid arbitrariness in legal decision making. Development of the theory of legal argumentation is closely related with development of law and philosophy in the middle of the Twentieth Century, emergence of scientific research method and social reality, an outcome of nomology research switching from exploring the whole macro significance of jurisprudence to research on the micro argumentation of legal norms, and is one of representations that the legal system is going toward maturity.

\section{The origin of thought for generation of the theory of legal argumentation}

The theory of legal argumentation is a research field which emerged in the academic fields in European and American countries in the $60 \mathrm{~s}$ and $70 \mathrm{~s}$ of the Twentieth century and got significant development. The contemporary origin of thought for its generation is the empirical analytical jurisprudence and practical philosophical thought. Argumentation theory originated from development of analytical jurisprudence. Ever since the $18^{\text {th }}$ Century when the British Philosopher Hume pointed out that there was no necessary connection between fact and value (that is, there was no necessary connection between "be" and "should be"), the traditional knowledge theory system about alliance of knowledge and morality has been thoroughly overthrown, which directly led to emergence of positivism and hastened generation of positivist jurisprudence. From then on, legal research that was merely based on the research stand of law itself became the mainstream discourse at that time. Both the legal command theory of Austin and the abstract jurisprudence theory of Kelsen were founded on the basis of separation of fact with value. in the deductive legal procedure of pursuing freedom of value, law and morality were separated. On the path where one attempted to break away from constraint of morality on development of law, advantages of legal positivism were given full play and natural law theory lost its glory in former days. Ever since the middle of the Twentieth Century, emergence of the positivism jurisprudence pushed forward switch of research thinking modes in law. That is to say, pursuit of scientificalness, accuracy and empiricalness of research thinking modes in law pushed forward generation and development of legal argumentation theory.

Renaissance of the practical philosophy in the 60s and 70s of the Twentieth Century infused new opportunities for the positivism. Practical philosophy refers to the philosophical research paradigm about just conducts of human being. Usually, issue of the law and issue of the morality are both seen as the issue of practice. The masterpiece "Critique of Practical Reason" by Kant was one which discussed the issue of practice. In the eyes of Kant, the issue of morality was an issue of practice, which could not be stipulated by experiential knowledge, and moral imperative was transcendental, but not experiential. (Ge Hongyi, 2004) Empirical research of law added rational constituents to the research stand in which law and morality were absolutely separated. However, it was faced up with new difficulties, since without morality and without appeal to just behavior, the legitimacy of law itself had no means to acquire perfect logic. Emergence of the Nazi regime and the Second World War in the Twentieth Century brought about economic depression to the whole world, which urged all the people around the world to survey again internal connection between law and morality. By that time, the famous representatives of analytical jurisprudence Hart and Fuller had intense dispute about law and morality, which rapidly aroused attention and participation of the law field in western countries. From then one, the issue of law and the issue of morality were presented to the whole world with a brand-new position, which returned to the practical philosophy and updated the development skeleton of analytical jurisprudence. "The renaissance practical philosophy no longer aimed at pursuing correspondence of behavioral meaning and objective truth, but resorted to such new research methods as hermeneutic and linguistics to provide theoretical support for construction of behavioral meaning and recover the moral significance of behavior through objectiveness of linguistic exchange and communication mechanism. In the meanwhile, legal positivism also was updated. That is to say, on the pre-condition persisting on the basic view of legal positivism, we keep certain openness to the practical issue of morality so as to adapt to the social development need of diversity and democracy." (Ge 
Hongyi, 2004) This research mode has become the new issue and new field in research of jurisprudence theory. Research by Hart and Dworkin was the typical case. Revival of the philosophy of positivism impels people to focus on legitimacy and legality of law itself, highlights the mode that legal research resorts to multiple scientific research methods to deduce theories and has enlightenment significance to study on legal argumentation.

In one word, the positivist jurisprudence offered a basic analytical structure for theory of legal argumentation and enabled legal argumentation to concentrate on the scientificalness, accuracy and empiricalness of research methods in research. Development of the practical philosophy enriched the research technique of the theory of legal argumentation and enabled research methods of law to be combined with hermeneutic method of philosophy and the general linguistic research methods in an organic way, which laid a foundation for the theory of legal argumentation to break through the traditional research methods and construct the value attribute of its practical theory.

\section{Origin of methodology for generation of the theory of legal argumentation}

Development of the theory of legal argumentation also depends on support of the diversified scientific research methods in terms of methodology in the middle of the Twentieth Century, especially research methods of logic, language and hermeneutic.

The research method of formal logic has profound influences upon legal argumentation. The mode of classical syllogism provides support in terms of methodology for jurists to demonstrate a legal conclusion and offers a path for people to demonstrate the logic relationship between a major premise, minor premise and a verdict conclusion. At its initial period, the theory of argumentation fit with the research scope of formal logic. Nowadays, the theory of legal argumentation embodies the characteristics of inheritance and criticism of the research method of the traditional formal logic. On one hand, legal argumentation inherits the research method of logic in research of formal justice and pursues the logic justice between premise and conclusion. The theory of internal justification about legal argumentation by Alexy used the research method of logic to a great extent. On the other hand, the theory of legal argumentation combines pursuit of formal justice and pursuit of material justice, concentrates on the rationality of the starting point (major premise) of logic research, seeks for material justice of a verdict with the method of moral statement and offers more extensive research interest for development of legal argumentation. In the legal argumentation, logic is a kind of tool to evaluate whether a person has successfully proved that a certain verdict has to be accepted by an audience with rational behaviors (Eveline T. Feteris, 2005, p25). The research method of logic reveals justice of judicial verdict conclusion in terms of the formal dimension.

The research method of language opens a new vision for the theory of legal argumentation. A legal norm always resorts to a language symbol (written or oral) to make it public, while complexity and limit of language makes troubles in the process of legal explanation and application. In its process of development, western philosophy has undergone two far-reaching diversions, namely, diversion of epistemology and diversion of language. The first diversion made the foundation of philosophy transfer from ontology and metaphysics to epistemology and from research on transcendent existence to study on relationship between the subject and object of cognition. By contrast, the second diversion changed from study on the object to grasp of the issue of communication and exchange between subjects and changed study on the subject from the psychological field to the linguistic field (Jiao Baoqian, 2006, p21). In the Twentieth Century, philosophical development broke through the binary framework of traditional cognitive activity and language expression, and focused on use of language and symbol and on communication between the subject and the object. In study on jurisprudence, Hart brought in the research method of language, put forward that fuzzy phenomena in terms of language existed in understanding of law and proposed distinguishing research tactics of simple case and tough case. At that time, research of textualism represented by Heidegger and Gadamer was also prevailing and became the important means to overcome disadvantages of traditional scientific research and the important means to observe, understand and explain the world. Use of language bears the important task of exchanging human thought. Human experience can not go without language and social justice calls for communication and exchange. Language symbols shed light on leap of human experience from "monologue" to "dialogue". Usage of the research method of language offers new research tool for emergence and development of the theory of legal argumentation. The procedural (Beratung) legal argumentation theory by Alexy, the justification theory of legal decision by MacCormick and the legal conversion theory by Peczenik all displayed application of the research method of language in judicial verdict.

In the middle of the Twentieth Century, the research method of hermeneutic that had been prevailing in the western world also became a systematic research method, which took as its task revealing the significance of the 
world and was established in the natural scientific concept and thinking mode. Usage of this research method of hermeneutic in jurisprudence also exists in research of natural law and research of positive jurisprudence, but it has drawbacks which itself is unlikely to overcome, namely, the serious deviation and "spiritual split" (Zhu Qingyu, 2002) of jurisprudence epistemology and jurisprudence methodology with jurisprudence ontology. Application of the science of hermeneutic is quite important in jurisprudence, and legal application and legal interpretation exhibit a positive correlation. However, hermeneutic is also faced up with the weakness it has no way to overcome: how could hermeneutic acquire recognition? Legal argumentation can not go without explanation of a legal norm and at the same time, it is committed to how to explore a method which recognizes the explanatory result. The theory of legal argumentation has close relationship with the research method of hermeneutic and is a research field that newly arose after diversion of legal hermeneutic. In Japan, it is on the basis of legal hermeneutic dispute after the war that the theory of legal argumentation was gradually developed. The justification theory of legal explanation by Aarnio fully indicates the value and status of the research method of hermeneutic in research of legal argumentation theory.

The research methods of logic, language and hermeneutic have provided support in terms of methodology for production and development of legal argumentation, encourages the theory of legal argumentation to surpass the research mode in which the traditional jurisprudence research appealed to the abstract meaning and offers research tools for converting of the theory of legal argumentation to research on the legitimacy and legality of a legal norm and legal decision result.

\section{References}

Eveline T·Feteris. (2005). Foundamentals of Legal Argumentation:A Survey of Theories on Justification of Judicial Decisions. The Commercial Press, September.

Ge, Hongyi. (2004). A Tentative Study on the Source, Evolution and Purport of Legal Demonstration. Law Science, No. 5.

Ge, Hongyi. (2004). The Concept,Significance and Method of Law Argumentation. Zhejiang Social Sciences, No. 2.

Gu, Zhenxie. (2001). Argumentation and Analysis --- Application of Logic. People's Publishing House.

Jiao, Baoqian. (2006). Introductory Theory of Legal Argumentation. Shandong People's Publishing House, $1^{\text {st }}$ Edition, August.

Robert Alexy. (2002). Theorie der Juristischen Argumentation, translated by Shu, Guoying. China Legal Publishing House, December.

Xia, Zhenpeng. (2004). Introduction to Legal Argumentation, in Legal Method, Vol. 3. Shandong People's Publishing House.

Zhu, Qingyu. (2002). The Hermeneutic Theory of Declaration of Intention --- Reasoning Theory of Civil Law in the Horizon of Philosophical Hermeneutics and Rhetoric. PHD Thesis of China University of Political Science and Law. 